\title{
STUDY OF INJURY PATTERN IN HUMAN BEINGS IN ROAD TRAFFIC ACCIDENTS INVOLVING TWO WHEELERS
}

M. Seethalakshmi1 ${ }^{1}$ R. Sudalaimuthu², J. Mahendran³, A. Nagendrakumar ${ }^{4}$

\section{HOW TO CITE THIS ARTICLE:}

M. Seethalakshmi, R. Sudalaimuthu, J. Mahendran, A. Nagendrakumar. "Study of Injury Pattern in Human Beings in Road Traffic Accidents Involving Two Wheelers". Journal of Evolution of Medical and Dental Sciences 2015; Vol.4, Issue77, September 24; Page: 13436-13458, DOI:10.14260/jemds/2015/1927

ABSTRACT: India experienced very rapid population growth from 48 million to 1.2 billion in a span of decades. In India rapid urbanization, industrialization, population explosion and migration of people in past two decades results in enormous growth in the field of road transportation. This resulted in increasing amount of the road traffic leading to increased risk for occurrence of road traffic accidents. In India road traffic injuries will be third leading cause of death by 2020 with the increase in the use of two wheelers and congestion and environmental pollution this mortality rate will continue to rise. Considering the preciousness of human lives, this study has been undertaken to analyse the pattern of injuries in Road Traffic Accidents Involving Two Wheelers to create awareness among the law enforcing authorities, transport authorities and public regarding two wheeler fatalities. A sincere attempt has been made in this study to analyse the distribution of the pattern of injuries sustained by two wheeler travellers, so that appropriate interventional strategies can be evolved at various levels and by different agencies. 147 Two wheeler Accident victims were randomly selected from 1063 road traffic accident cases brought to the Institute of Forensic Medicine, Madras Medical College Chennai-3 for routine medico legal examination. Preliminary data were collected from the medico legal documents such as history of the case, Inquest form, First Information Report, Accident Register, Death Report, Clinical data submitted by the investigating officer at the time of medico legal examination. During autopsy, on external examination, nature of injury, size, number were measured in all cases. Internal organ injuries were recorded. Cause of death was arrived at based on the findings made out during autopsy. Totally 147 motorcyclist victims were included in this study in which demographic factors such as age, sex, time of accident, manner of collision, period of survival, injury pattern were analysed. Total number of helmet users and non-helmet users and pattern of injuries were analysed. External and internal injuries among the victims were analysed according the different regions of the body. Pattern of fatal injuries and the cause of death were also analysed. Data collected were entered into excel sheets and statistical analysis was done using SPSS software version 16 and conclusions were arrived. With the help of this study, analysis and conclusions, recommendations for road safety policies were sought.

KEYWORDS: Injury pattern, Road Traffic Accidents, Two wheelers.

INTRODUCTION: India experienced very rapid population growth from 48 million to 1.2 billion in a span of decades. In India rapid urbanization, industrialization, population explosion and migration of people in past two decades results in enormous growth in the field of road transportation. This resulted in increasing amount of the road traffic leading to increased risk for occurrence of road traffic accidents.

Nearly 1.3 million people die every year globally due to road traffic accidents (RTA) world health organization in its report projected that fatalities due to RTA is expected to by 1.9 million in 


\section{ORIGINAL ARTICLE}

2020. In India road traffic injuries will be third leading cause of death by 2020 with the increase in the use of two wheelers and congestion and environmental pollution this mortality rate will continue to rise.

People prefer motorized two wheelers for various reasons with travelers opting for a powered two wheelers as a cost efficient alternative to expensive and less frequent public transport systems their fuel efficiency convenience for short distance travel with one or two persons especially at the peak hours as a means of reducing or avoiding the effects of congestion etc. Lance splitting permits the motor vehicles to move through the space between the vehicles in the stationary or slow traffic. ${ }^{1}$

Motorcyclists experience a 35 times greater death rate than the occupants of cars. The latest data released by the Govt. of India, Ministry of Home Affairs has revealed that $21 \%$ of the road death victims in 2009 in the country were riding two-wheelers. Due to enormous increase in two wheeler collisions, the frequency of doing autopsy on road traffic accident cases by forensic pathologist increases many fold. Autopsy on victims of motor vehicle accidents helps to determine the time of accident, period of survival, manner of accidents, history, collection of trace evidence to identify the site of accident etc.

Factors predisposing Road Traffic Injuries are classified into Agent, Human and Environmental. Analysis of this Epidemiological Triad is crucial to develop and implement mechanisms for control and prevention of fatal injuries.

Considering the preciousness of human lives, this study has been undertaken to analyze the pattern of injuries in Road Traffic Accidents Involving Two Wheelers. Aim of conducting this study is to create awareness among the law enforcing authorities, transport authorities and public regarding two wheeler fatalities. A sincere attempt has been made in this study to analyze the distribution of the pattern of injuries sustained by two wheeler travelers, so that appropriate interventional strategies can be evolved at various levels and by different agencies.

\section{AIMS AND OBJECTIVES:}

- To study and analyse the pattern of injuries case of victims of two wheeler accidents.

- To study influence of various physical factors in vehicular accidents involving two wheelers.

- To study the survival period of victims of two wheeler accidents.

- To assess the effectiveness of protection offered by wearing helmet.

- To compare the results obtained with similar studies.

REVIEW OF LITERATURE: History of occurrence of Road Traffic Accidents goes before the invention of motorized vehicle. With the invention of automobiles, the number of road traffic accidents grew exponentially. The first recorded case of road traffic injury was on 30 may 1896 by the cyclist in New York City U.S.A. ${ }^{3}$ Road traffic accidents constitute a major epidemic among the non-communicable diseases in the present century.

Road traffic Accident is defined as an accident which took place on the road between two or more objects, one of which must be any kind of moving vehicle. According to the United States National Highway Traffic Safety Administration (NHTSA), in 2006, the fatal crashes rate of car was $13.10 / 100,000$ whereas for motorcycles $72.34 / 100,000.4$ According to ATS, the rate of serious injuries for motorcycles per 100 million vehicle kilometers was 16 times higher than cars, and twice 
than bicycles. Motorcyclists they are 30 times more prone than drivers of other vechicles ${ }^{5}$. Motorcyclists are more prone for serious vulnerable road traffic accidents due to inherent instability of two wheeled vehicles. ${ }^{6}$ The annual growth rate of motor vehicle registration in India is $10.6 \% .^{7}$

Age: Age is an important factor influencing the occurrence of road traffic accidents involving motor cycle. Road traffic accidents ranks among the three leading cause of death in the age group 5-44 years. Two wheelers accident deaths among individual aged above 60yrs are also low due to less mobility of the people. ${ }^{8}$

ZengHao Wong et al. 2009 reported in their study that median age of accident victims was 36 yrs. ${ }^{9}$ Riders aged below 40 have 36 times higher risk of death and those aged above 40 years have 20 times higher risk of death when compared to other drivers of same age. 5 Jain A et al, 2009 stated that $77 \%$ of his sample belong to age group 19-44 yrs.10

According to Michael Fitzharris et al, the mean age was 31.3 yrs12. Kortor JN et al in 2010 reported that the mean age of the victims in the sample was 43.112 .

Gender: Road traffic accidents are the most common cause of death in the population. Males are the earning members of the family more often subjected to work related stress more exposed to the outside environment.

Menon et al 2008 showed marked male preponderance in toad accidents victims. The reason of male predominance could probably be due to the tendency of violating the traffic rules and regulations, and possession of fake driving licenses. ${ }^{13}$

H.Markogiannakis et al has reported that, young men constituted the majority of injured motorcyclists among the adult trauma patients of Herakleion University hospital. Zargar $\mathrm{M}$ et al in reported that among 8500 patients admitted in trauma care ward, 1332 were motorcyclists, with a male to female ration of 15: $1 .{ }^{14}$ Dischinger PC et al and Dolinak et al stated that males are most common road traffic accident victim. ${ }^{15,16}$

ZengHao Wong et al in 2009 reported that majority were male in their victim samples.10 Michael Fitzharriser al 2009 reported that $88.1 \%$ of the victims of their samples were male and $97.2 \%$ were riders and $69.8 \%$ were pillion riders.

Martin JL el al in 2004 reported that the incident rate of male of female is 3.1 for mortality and 1.7 for morbidity. The fatality rate and severe injuries rate is higher for male when compared to females among the survivours. ${ }^{17}$

Fatigue: Factors that predispose a driver to fatigue include drivers aged above 50 years, associated medical conditions such as narcolepsy, riding with sleep deprivation for more than 16 hours of wakefulness before trip, riding motorcycle after poor-quality sleep, irregular shift work periods and successive nights of shift work. Some riders are drowsy in the afternoon, breakdowns of the vehicle, extreme climatic conditions, long main arterial roads, monotonous roads, riding after consuming alcohol, riding under time pressure, riding on an unfamiliar route etc.

Oginni FO et al., 2009 reported in their study that 13.5\% accidents of their sample victims were contributed by their fatigue ${ }^{18}$. ValentFet al., 2009 found a decrease in the relative risk of accident was associated with sleeping >= 11 hours daily an increase in the relative risk was associated with non-sleepy of $>=16$ hours. ${ }^{19}$ 


\section{ORIGINAL ARTICLE}

Alcohol: Alcohol affects driving efficiency enormously so that safe driving is seriously affected. This is due to a drop in the reaction time and the drunken driver will take 15 to $20 \%$ more time to press the brake or change the gear, when required. It impairs the concentration and dulls the power of judgment. It creates increase in false and unjustified confidence. It affects the vision, as the visual acuity gets diminished depending upon blood alcohol concentration. With high alcohol concentration, stronger illumination will be required for distinguishing objects and also affects the peripheral vision. ${ }^{10}$

OginniFo et al., 2009 reported in their study that in $31.2 \%$ of riders, alcohol was implicated 20 . Michael Fitzharris et al 2009 reported in their study that there was no significant difference of alcohol consumption in the distribution of riders (55.6\%) and pillion riders (52\%). ${ }^{11}$

Harry Hurt et al., 2011 reported that almost half of the fatal accidents show alcohol involvement. ${ }^{6}$ About $85 \%$ victims of night time crashes have their blood alcohol levels sufficient to influence them. ${ }^{20}$ Cherpitel $\mathrm{CJ}$ et al., 2003 reported a clear association between alchol and injury especially for road traffic injury within six hours of alcohol consumption. ${ }^{21}$

Gururaj G er al. 2004 reported $40 \%$ of night time crashes and 22\% of subjects were under alcohol influence. $51 \%$ of cases were two wheeler occupants' death. Disability and severity higher in alcohol positive subjects. ${ }^{22}$

Rider/Pillion Rider:Bikers never care about the race, religion, caste but only think about riding. Young males prefer to ride motorcycles. The pillions are usually children, females and older ones. Rider's factors determine the road traffic collisions such as attention, reaction time, alcohol consumption, co-morbid conditions like epilepsy, myocardial infarction, vision impairment etc. Dandona $\mathrm{R}$ et al concluded that riders of motor cycles have a higher risk of two thirds of skid and fall are due to excessive speed, over braking etc.

Michael Fitzharris et al., 2009 reported that $66.7 \%$ of the victims of their samples were riders. $56.1 \%$ of motorized two wheeled vehicles were motor cycle whereas $38.6 \%$ were scooters, $5.3 \%$ were mopeds with no difference in riders and pillion riders in vehicle type. ${ }^{11}$ No difference in the severity of the distribution of the injuries, fatality survival outcome in the riders and pillion riders. The risk of injury differed among the riders and pillion riders except in that the crush injuries of the lower extremities lower for riders than the pillion riders. Female pillions tend to have lower risk of fractures of the lower limbs when compared to the male pillions, since the female sit sideways across the seat whereas the male pillions sit facing forward. ${ }^{23}$

Hui Zhao et al 2011, reported that in riders, some characteristic superficial injuries were seen in the palm, chest abdomen as well as the perinealarea, which were not seen in pillion riders. ${ }^{24}$ Pillion riders are often involved in collisions between motor cycles and four wheelers. ${ }^{25}$

Marital status Education: Michael Fitzharris et al in 2009 reported that the distribution of rider/ pillion rider is not affected by marital or educational status ${ }^{11}$.

Monthly Income: R Dandona et al., 2006 reported that, 52.4\% among their samples were the main source of income earner of their family, $41 \%$ of the people included in their study had their per capita monthly household income of Rs. 2000 or less, $28.2 \%$ had their monthly household income of Rs 2001 to Rs 4000, 15.1\% had their monthly household income of more than Rs.4000.26 


\section{ORIGINAL ARTICLE}

Helmet:Nearly $50 \%$ of the motorcycle riders in traffic were using safety helmets but only $40 \%$ of the accident-involved motorcycle riders were wearing helmets at the time of the accident. Safety helmet use by those accident- involved motorcycle riders was lowest for untrained, uneducated, young motorcycle riders on hot days and short trips. The most fatal injuries to the accident victims were injuries to the chest and head. The safety helmet use is the single critical factor in the prevention and reduction of head trauma; the safety helmet which complies with FMVSS 218 is a significantly effective injury countermeasure. It caused no attenuation of critical traffic sounds, no restriction of pre-crash visual field, and no fatigue or loss of attention. FMVSS 218 provides a high level of protection in traffic accidents, and needs modification only to increase coverage at the back of the head and demonstrate impact protection of the front of full facial coverage helmets, and ensure all adult sizes for traffic use are covered by the standard. Helmeted riders and passengers showed significantly lower head and neck injury for all types of colloisions. ${ }^{11}$

Zargar $m$ et al in 2006, in their study reported that only $2.7 \%$ of helmeted riders had a head injury, compared with $11.2 \%$ of riders without a helmet28. Michael Fitzharris et al 2009 reported in their study that non helmet users were 1.9 times risk of acquiring open wounds of the head and five times more prone to sustain intracranial injury. Also in this study, among the 19 pre-hospital deaths 16 were not wearing helmet. Among female pillion riders only one was wearing a helmet ${ }^{11}$. Helmet users had a much lower incidence and severity of head injury than riders who did not wear helmets. Turbans appeared to offer partial protection from head injury. ${ }^{11}$

Type of Collisions:Victims involved in collisions with other powered vehicles sustained 36\% more fractures and higher Injuries Severity Score, when compared with accidents where no collision occurred with a powered vehicle. Motor cycle Collisions more frequently involve Light motor vehicles.

Peek- Asa concluded that $55.5 \%$ of collisions occur between motorcycles and cars or other heavy vehicles and $18 \%$ of accidents are due to motorcycle falls. Motorcycle running over a pedestrian/ animal (8.8\%), Motorcycle Vs Motorcycle (4.9\%), Motorcycle Vs Heavy vehicle (5.7\%), Motor vehicle Vs Non Motor vehicle (5.4\%), Motorcycle Vs Fixed object (1.7\%). Death frequencies are higher in collision with fixed objects and heavy vechicles. ${ }^{28}$

$\mathrm{R}$ Dandona et al in 2006 reported in their study that about $4.4 \%$ of the persons were either a pedestrian or a MTV user during the last one year in the most recent road traffic collision and $83.5 \%$ were MTV users. ${ }^{26}$

Michael Fitzharris et al in 2009, reported in their study that single vehicle accidents are mostly due to skidding, which is most often by avoidance manoeuvres, loss of control and striking fixed road objects. In multiple vehicle collisions buses and trucks are commonly involved. ${ }^{11}$

Peek-Asa C, Kraus JF in 1996, concluded in their study that the main factor in the collision involving multiple vehicles was the difficulty in the drivers part in noticing the proximity of motor cycles since the motor cycle is narrow and approximately deciding the time to act avoid colliding. ${ }^{28}$

Harry Hurt et al, grease n Gasoline, 2011, reported that approximately three-fourths of motorcycle accidents involved collision with another vehicle which was most usually a passenger automobile. Approximately one-fourth of these motorcycle accidents were single vehicle accidents involving the motorcycle colliding with the roadway or some fixed object in the environment? 


\section{ORIGINAL ARTICLE}

Manner of collision: In frontal collision, the rider of a vehicle continues to move forward as the vehicle abruptly comes to a stop. This forward motion is arrested as the victim connects with the stationary vehicle. The initial impact point is often the lower extremities, resulting in fracture/dislocation of the ankles, knee or hip dislocations and femoral fractures. ${ }^{2}$ In lateral collisions the victim is accelerated away from the side of the vehicle. Compressive pelvic injuries, pulmonary contusion, intra-abdominal solid organ injuries and diaphragmatic rupture are common. ${ }^{2}$ Rear impacts also accelerate the victim as the inertia of the head makes the cervical spine more prone for the injury. Ejection from a vehicle is associated with a significantly greater incidence of fatal injuries. ${ }^{2}$

R Dandona, in 2006 have reported in their study35.2\% as broadside collisions, side collision (16\%), Motorcycle falls (18\%), Cross collisions (35.2\%), Lateral collisions (16\%), Rear end collisions (12.6\%), Collision with pedestrian (6.6\%), Multiple impacts (4.9\%), Head in collisions (2.9\%), Collision with animals (2.1\%), Collision will a fixed object $(1.7 \%)$. High percentage of severe injuries and deaths was noted in head on collisions. ${ }^{29}$

Peek-Asa C, Kraus JF in 1996, in their study compared the riders in left turning motorcycles with other left turning vehicles. Motorcyclists had increased lower extremity and abdominal injuries and lower frequency of head, chest and facial injuries than riders of other crash types. The risk for lower extremity fractures was high among riders in broadside collisions and also in multiple-vehicle collisions than single-vehicle collisions. ${ }^{28}$

Speed: In general, greater the speed at the moment of collision, greater will be the injury severity. Excess Speed" is defined as a vehicle exceeding the relevant speed limit; "inappropriate speed" refers to a vehicle travelling at a speed not suitable for the prevailing road and traffic conditions.

Accident risk increases as the speed increases, particularly at road junctions and while overtaking-as road users underestimate the speed, and overestimate the distance, of an approaching vehicle. The probability of a crash involving an injury is proportional to the square of the speed. The probability of a fatal crash is related to the fourth power of the speed.

Javouhey E et al, in 2006, reported that on colliding with fixed object or any other motorized vehicles there are a high risk of injuries and death, usually due to excessive speed, correlated to the high level of energy ${ }^{30}$. Peel-Asa C, Kraus JF., 1996 reported in their study that the higher risk of severe injuries and fatalities are due to excessive speed and also when correlated to the level of energy.28

License: Danona R et al., 2006 reported that 11\% motorcycle riders participated in their study had not obtained driving license. $21.4 \%$ had obtained license without mandatory driving test. ${ }^{26}$

Rear View Mirror: Dandona R et al., 2006 in their study found out 49\% of the motorcycles had no rear view mirror. ${ }^{26}$

Environment: Area, illumination, condition, traffic sign, reaction time, and conspicuity: Season, day/night, types of the road, presence of traffic police, improper lane discipline curves, domestic animal interventions, pedestrian intervention etc influence the accidents. Road illumination is one of the important factors related to collisions. Data from a study carried out in China revealed that illumination is related to fatal accidents and severity of injuries. Unfavorable local conditions allow vehicle collisions to occur more frequently. 


\section{ORIGINAL ARTICLE}

Road factors include road width, alignment, gradient, surroundings, lay out marking, surface quality etc. Weather, Surface condition, natural light, road lighting, signs, speed limit enforcement etc.

Oginni FO et al., 2009 reported that among motorcycle injured Nigerian maxillofacial patients, $17.6 \%$ of motorcycle accidents were attributed by bad roads. ${ }^{18}$

Time of Accidents: Michael Fitzharriser al 2009, reported that among 59\% of two wheeler accidents involving multiple vehicles, $40 \%$ occurred in the evening, $21 \%$ between midnight and 6 in the morning. ${ }^{11}$

De Oliveira Nl, de Sousa RM in 2011 reported that $36.5 \%$ of collisions occurred between 12pm and 5: $59 \mathrm{pm} ; 30 \%$ occurred between $6 \mathrm{pm}$ and 11: $59 \mathrm{pm}$. Frequency of accidents are same on Fridays (16.9\%) and Saturdays (16.6\%), lowest on Sunday (10.8\%). ${ }^{31}$

Period of Survival: Nearly $50-60 \%$ of all road traffic fatalities occurs immediately at the spot or while transferring to a hospital. Nearly $20-30 \%$ dies during hospital stay and $5-10 \%$ after discharge from the hospital.

Another study among 378 MTV riders and pillions, 1.6\% were spot death, $3.2 \%$ died on their way to hospital and $95.2 \%$ reached the hospital.11

Conspicuity: Rider conspicuity increased by fluorescent clothing, while or light colored helmets and headlights on during daytime, wearing reflective or fluorescent clothing reduced the risk of a crash injury by $37 \%$, a white helmet by $24 \%$, and riding with headlights on by $27 \% .^{32}$

De Oliveira $\mathrm{Nl}$, de Sousa $\mathrm{RM}$ in 2011 reported that $86 \%$ motor cycle fatalities occurred in urban and $14 \%$ in rural areas. In rural areas victims conditions are more severe than in urban areas due to lack of appropriate traffic sign surveillance and high speed. $77.8 \%$ motor cycle fatalities occurred in the appropriate illuminated areas, $22 \%$ in the inappropriate illuminated areass 21 within just less than 2 seconds.

Hand-Held Mobile Phones: The frequency of usage of hand-held mobile phones related accidents has increased to unprecedented levels over the past few years. In U.S.A the number of such cellular phones have increased from half a million to over 162 million during the period 1985 to 2004. It pose higher risk due to the following reasons: Longer reaction time, difficulty to maintain appropriate speeds, correct positions in traffic lanes, in judging, accepting safe gaps in traffic. Drivers using cellular phones face four times higher risk of crash than other drivers. ${ }^{33}$

Injury: A majority of medico legal autopsies in India are carried out on the victims of vehicular accidents. RTA comprise of mostly injuries to the limbs, face, externally; while more commonly head sustained internal injuries. A careful examination of injuries sustained is necessary for the reconstruction of the accident. From the nature of the injuries inferences can be drawn regarding the relative positions of the victim and the vehicle at the time of accident. Moreover in 'hit and run' cases, the nature of injuries and collection of trace evidence the decedent will help to connect the suspect vehicle with the crime. It may also be possible to give an opinion as whether the vehicle had run over the victim. 


\section{ORIGINAL ARTICLE}

Definition: An injury is any harm, whatever illegally caused to any person in body, mind, reputation or property (sec. 44, I.P.C.).

The Injury Severity Score (ISS) in an anatomical scoring system that provided an overall score for patients with multiple injuries. Each injury is assigned an Abbreviated Injury Score (AIS) and is allocated to one of six body regions (Head, Face, Chest, Abdomen, Extremities (including Pelvis). Only the AIS score highest in each body region is used. The most severely 3 injured body regions have their score squared and added together to produce the ISS score.

Mechanism of Production of Injury: Due to impact between the forward moving force and the counter force, energy is transferred to the tissues of the body, which cause change in the state of rest or motion. It is the rate if change if movement either acceleration or deceleration due to trauma cause displacement and deformation and traction strains in the affected tissues. Tissues vary in their resisting capacity in acquiring injuries.

Pattern of Injuries in Fatal Two Wheeler Accidents:Dr.S.S.Oberoi at al., 2011 concluded that $31.34 \%$ injuries are contributed by fractures, $29.85 \%$ by abrasions, $29.10 \%$ by lacerations, $9.7 \%$ by contusions. 25

Regional Distribution of Injuries:Collisions may be head on collisions, rear impacts, side sweeps and roll-overs. Due to the instability of the vehicle, when collision occurs the victim is ejected from the vehicle, he often strikes his head on to ground. Impact with the road surface or against another vehicle results in head injuries, limb injuries, thoracic, abdominal, pelvic, spinal cord, upper and lower extremity injuries.

In case of inter section type of collisions, where the motor cyclist strikes the side of an automobile, he moves forwards striking the fuel tank, while the pelvis lifts from the seat and the head strikes the side of the vehicle close to the roof of the opposite vehicle. So the primary impact injuries like abrasion, contusions and lacerations are most commonly seen in the areas of inner aspects of thighs and perineum. This is possible because of the friction of the thighs and perineum with the fuel tank. Pelvic fractures and perinea lacerations are also very common due to the impact on of the handles bar of his own two wheeler. The next common regions affected by primary impact are upper extremities and shoulder, whereas abdomen, head and neck are less commonly involved regions. Secondary impact injuries are mostly seen in the head and neck, followed by upper extremities whereas, back and abdomen are the least involved.

Fractures occurring in skull of the motorcyclist can be summarized as follows:

- Fall on the side with side impact to the head causes Basal Skull fracture.

- Fractures especially Hinge type also called Motor Cyclists Fracture. ${ }^{32}$

- Head injury and disabling leg and foot injuries are among the fatal injuries that motorcyclist's suffer. $^{7}$

Dr. S. S.Oberoi et al., 2011 concluded that $66 \%$ fatal injuries are seen in head/ face, $12 \%$ in chest, $8 \%$ in abdomen. ${ }^{34}$

Head Injury: Head injuries are extremely common among the road traffic accident victims. Craniocerebral injuries are the predominant and fatal injuries among the motor cyclists accounting for $80 \%$ of deaths. In adults, cranium varies in thickness and varies from place to place. Most common site of 


\section{ORIGINAL ARTICLE}

fracture is temporo-parietal region. In RTI, force is transmitted to a wider area and when sufficient to exceed the elastic limits of the skull, fractures may commence from the site of impact or from the area remote to the sire of impact, or commencing ar a distance and run back to the sire of impact. A heavy impact on the skull, fracture the vault of the skull running into the base of the skull usually the floor of the Middle Cranial Fossa, separating the floor into halves termed hinge fracture also termed as Motor Cyclists fracture.

$\mathrm{H}$ Markogiannakis et al reported that Cranio-cerebral injuries are the primary cause of death (73.3\%) among the motorcyclsit35. Most deaths due to head injuries involved temporal bone (76.34\%) and occipital bone was involved in less number of cases $(9.14 \%) .{ }^{34}$

Many series of motor cyclists said, $60 \%$ had skull fractures and $80 \%$ had brain damage. Common injury of the riders of motor cycles is the 'Tail-Gating' where the rider drives into the back of a truck so that they pass underneatj, but the head of the impacts upon the tail-board.

Complications of Skull Fracture: These include concussion, compression, contusion and lacerations of brain.

Meningeal Injury: At the moment of impact, the skull moves relative to dura beneath it, and the dura is stripped from the bone. Any of the three layers of meninges can be torn by the edges of fractured fragments of skull or by the penetrating objects. However, pia matter and arachnoid matter can also be ruptured due to the accumulation of blood underneath. Contents of the skull are the most fragile of the vital organs.

The Acceleration or Deceleration forces with a rotational element cause brain damage. Hal bourn postulates that the brain tissue is injured when its constituent particles are pulled so far a[Art that do not join up again properly when the blow is over. In the brain, this pulling apart is proportional to the shear strains. When the head is rotated by an impact, the layers of brain tissue slide may either slide over each other causing damage to blood vessels resulting in intra-cerebral hemorrhages, contusions or may tear due to shearing forces causing lacerations. Intracranial hemorrhaged includes hemorrhaged occurring within the cranial cavity. Fracture of the skull bones, though is the common cause of intracranial hemorrhaged, the hemorrhaged can occur even without fracture of any of the skull bone fracture.

Intracranial hemorrhaged

i. Intra-axial Haemorrhage: Intra-cerebral haemorrhage and inter-ventricular haemorrhage.

ii. Extra-axial Haemorrhage: Extradural Haemorrhage, Epidural Haemorrhage, Subdural Haemorrhage and Subarachnoid Haemorrhage.

Arvind Kumar et al, noted that from his study Subdural haemorrhage 89\%, followed by subarachnoid haemorrhage $72 \%$ extramural $20.25 \% .{ }^{36,29}$

Among 79 cases, 34 victims had linear fracture, 14 had basilar fracture, 6 had communised fracture, 3 had depressed fracture, 4 had crush fracture and 18 had no fracture ${ }^{38}$.

Upper and lower Limb Injuries: B Knight: Legs are injured either by primary impact with another vehicle or fixed road structures or by being trapped into the parts of the vehicle frame. Common injuries are lacerations, friction burns and fractures.

Kortor JN al., 2010 in a study reported that the lower limb injuries are the common, accounting for about $55.5 \%$ of injuries. Fractures constitute $73.34 \%$ of lower limb injuries, with 


\section{ORIGINAL ARTICLE}

closed fractures were commoner than the open fractures. The commonest bone involved was tibial shaft. 12

Aslam M et al., 2008 said that the patients presenting with tibial injury were significantly higher than the bone injuries of other body part. In $26 \%$ of patients, fibula was also involved along with tibial fracture. Other were Femur 16\%, Radius 9.2\%, Humerus $8.3 \%$ Radius was the commonest injured bone and in highest proportion among upper limb injuries $(\mathrm{P}<0.001) .{ }^{39}$

Calil AM et al 2009 concluded that motorcycle users had a significantly higher number of injuries to the upper limbs, lower limbs and pelvis compared to other victims, while there were more head/ neck and face injuries in run-over automobile accidents. ${ }^{40}$

Latee $\mathrm{F}$ reported that among 1,809 motorcyclists studied, 1,056 (58.\%) sustained lower limb injuries, 328(18.1\%) had head injuries and 256 (14.2\%), sustained facial injuries. ${ }^{41}$

MichaekFitzharris et al 2009 concluded that only 1\% of male pillion riders sustained open wounds of the upper extremity as compared to $8 \%$ in female pillion riders. ${ }^{11}$

However female pillion riders (7.6\%) are at a lower of sustaining fractures of the lower extremity than pillion riders (26\%) because females tend to sit sideways across the seat than facing forward. ${ }^{11}$

Lower extremity injuries were diagnosed in 56\% of nonfatal injured and in $44 \%$ of fatally injured riders. Fractures were the most common lower extremity injury and were diagnosed in 52\% and $42 \%$ of riders with nonfatal and fatal injuries, respectively. Over a third of all fractures were to the tibia or fibula. Drivers and passengers did not differ in their risk for lower extremity injuries. Multiple-vehicle collisions resulted in a higher risk of lower extremity injuries than did single-vehicle collisions. The highest risk for lower extremity fracture was observed among riders in broadside collisions in which another vehicle struck the motorcycle. Peel C in 1994 concluded that lower extremity injures occurred in 56\% of non-fatal injuries, $46 \%$ in fatally injured riders. Fractures were the most common lower extremity injury occurred in 52\% and $42 \%$ if riders of fatal and non-fatal injuries, one third of fractures were tibia, fibula. ${ }^{26}$

Injury Pattern in Riders and Pillion Riders: Hui Zhao et al., in 2011 found the difference in the distribution between the riders and the pillion riders regarding the superficial injuries. For drivers than passengers, the injuries in the hand and perineum region were comparatively in high fraction ${ }^{24}$. Michael Fitzharris et al 2009 reported in their study that fracture of the head and neck region were higher in female pillion riders (18\%) ad compared to male pillion riders (6.8\%). ${ }^{11}$

Anish Sam Geroge et al., 2010, in their study reported that in riders the most common injuries of upper limbs were seen in wrist and hand and in the lower limbs over tibia and ankle whereas in pillion riders shoulder and wrist in upper limbs and tibia and ankle in lower limbs. ${ }^{25}$

Singh et al 2005 reported pillion riders sustained more fatalities when compared to rider's in. 42

Crush injury legs/Riders/Pillion Riders:Michael Fitzharris et al 2009 said that pillions have significantly higher risk of crush injuries of the lower extremities than riders. Female pillions have a lower risk of crush injuries than the male pillions. ${ }^{11}$

Trauma in road traffic accidents: The trauma sustained in transportation accidents can be classified according to the victim involved as trauma sustained by pedestrian, by cyclist/motor- 
cyclist, by occupants of vehicle. Injuries are Primary impact injuries, Secondary impact injuries and tertiary injuries. Tertiary injuries arise when the victim's body strikes the ground after the secondary impact.

Trauma sustained by Cyclist/Motorcyclist: The primary impact will be usually against some part of the motorcycle. Secondary impact and tertiary injuries are more severs. Examination of the motor cycle is also necessary from the cycle and from the body of the victim.

The incidence of injury and death amongst motorcyclists is far higher than among car drivers particularly in young adults.

Correlation of Post-Mortem Finding with roadside Evidence: Evaluation injuries sustained in a motor vehicular crash required the ability to recognize and distinguish between blunt and sharp force trauma. These are the two most common types of injury that occur in all types of motor vehicular crashes.

Police accident investigators are trained to furnish through reports, including witness statements. However, eyewitness accounts of a motor vehicle crash, in-fact any traumatic event involving sever injury or death, are often unreliable and sometimes conflicting. While such statements must be considered, they cannot indiscriminately be taken as factual. Eyewitness accounts are frequently tainted by emanations, sorrow and feelings of guilt, resulting in distorted, exaggerated and misleading information.

Therefore, correlation of autopsy findings with vehicular and roadside evidence is necessary. To achieve this goal it is advantageous for the investigating officer to attend the autopsy and perhaps for the pathologist to accompany the officer to personally observe the scene and the vehicle or vehicle involved in the crash, even after the fact, ager the vehicle have been removed. Only consideration of the injuries in light of roadside evidence will provide the background for proper evaluation of autopsy finding and assist in subsequent testimony.

MATERIALS AND METHODS: Collection of Samples: 147 two wheeler Accident victims were randomly selected from 1063 road traffic accident cases brought to the Institute of Forensic Medicine, Madras Medical College Chennai-3 for routine medico legal examination.

Study Design: Prospective study.

Period of Study: January - 2011 to October -2011.

Inclusion Criteria: Victims of Two Wheeler Motor vehicle accidents;

1. Rider/Pillion rider.

2. Hit by Light Motor Vehicle / Heavy Motor Vehicle / Self Fall.

3. Brought death directly to the casualty or died in the hospital in spite of treatment.

\section{Exclusion Criteria:}

1. Victims of motorcycles accidents other than riders and pillion riders.

2. Decomposed bodies of motorcycle accident victims.

3. Bodies which are severely mutilated.

4. Unknown bodies with vague history. 


\section{ORIGINAL ARTICLE}

Procedure: Preliminary data were collected from the medico legal documents such as history of the case, Inquest form, First Information Report, Accident Register, Death Report, Clinical data submitted by the investigating officer at the time of medico legal examination. During autopsy, on external examination, nature of injury, size, number were measured in all cases done by me. Internal organ injuries were recorded. Cause of death was arrived at based on the findings made out during autopsy. Data collected were entered into excel sheets and statistical analysis was done using SPSS software version 16.

RESULTS AND ANALYSIS: Totally 147 motorcyclist victims were included in this study in which demographic factors such as age, sex, time of accident, manner of collision, period of survival, injury pattern were analyzed. Total number of helmet users and non-helmet users and pattern of injuries were analyzed. External and internal injuries among the victims were analyzed according the different regions of the body. Pattern of fatal injuries and the cause of death were also analyzed.

Age Distribution of the Study Sample: Victims of age less than 20 years were found to be equal to $5(3.4 \%), 20-30$ years were 65(44.2\%), 30-40 years were $36(24.5 \%)$ and above 40 years were $41(27.89 \%)$.

Sex Distribution of the Study Sample: Out of 147 victims males comprised 138(94\%) and female comprised $9(6 \%)$. Significant no of victims of road traffic accidents were males.

Frequency of Riders and Pillion Riders: Total number of riders were 122(83\%) and pillion riders were $25(17 \%)$. Significant proportion among the riders were males $119(97.5 \%)$. P value $<0.05$. Females were 3(2.5\%). Among the pillion riders males were $19(76 \%)$ and females were 6(24\%).

Time of Accident: Among the total accidents 6 occurred between 3 and 6 AM, 27 between 6 and 11 AM, 28 between 11 AM and 3 PM, 21 occurred between 3 PM and 6 PM, 43 from 6 PM to 10 PM and 22 occurred between $10 \mathrm{PM}$ and $3 \mathrm{AM}$.

Percentage of fatalities among riders peaks during 6 to $10 \mathrm{PM}$ viz., $31 \%$ while percentage of fatalities among pillion riders peaks during 6 to 11 AM viz., $40 \%$.

Among those got hurt by self-fall who were 43 (29.25\%) in number 19 (44\%) of accidents occurred between 6 and 10 PM out of which only 1 is a pillion rider.

Manner of the Accident: Out of 147 cases, manner was known for 72 cases 49\%. 61/72 were frontal and $11 / 72$ were rear collisions.

Out of known 49\%, 84.7\% had frontal impact and 15.3\% had rear impact. Among 72 cases, 60 (85\%) are riders whereas $12(15 \%)$ are pillion riders.

Survival Period of the Victims: Regarding the survival period of the victims, $2(1.3 \%)$ were spot dead and $1(0.6 \%)$ was brought dead. Those who survived less than $12 \mathrm{hrs}$ were $40(27.2 \%)$, between 12 to $24 \mathrm{hrs}$ were $9(6.1 \%), 1$ to 4 days were 56(38\%), 4 to 14 days were $29(19.7 \%)$ and above 14 days were $10(6.8 \%)$ in number.

More fatalities within short period of interval occurred in less than $12 \mathrm{hrs}$ viz., 40 (27.2\%). 


\section{ORIGINAL ARTICLE}

Regional Distribution of Injuries: Among the external injuries, abrasions were seen 63 cases over Head and neck, 94 cases over Upper limb, 96 cases over Lower limb and in only 14 cases over Thoraco-abdominal region.

Contusions were 100 cases over Head and neck, 20 cases over Lipper limb, 6 cases over Thoraco - abdominal region and in only 4 cases over Lower limb.

Lacerations were seen 50 cases over Head and neck, 24 cases over Lower limb, 9 cases over Thoraco - abdominal region and in only 3 cases over Upper limb.

Fractures were seen 85 cases Head and neck, 24 cases over Lower limb, 26 cases over Thoraco - abdominal region and 17 cases over Upper limb.

Distribution of Abrasions: Out of 147 cases 55-70 \% of the abrasions all over the body were found on the right side of the body.

Injuries of Head and Neck: Head and neck injuries were distributed as abrasions in 63 cases, contusions in 100 cases, lacerations in 50 cases, Skull fractures in 74 cases, meningeal hemorrhages in 105 cases, cerebral in 24 cases and surgical intervention were done in 23 cases. Meningeal hemorrhages and contusions lead the run.

Among the fractures of the skull Temporal bone suffers the most with $40.13 \%$ followed by Frontal bone with $14.96 \%$. Occipital bone is the least affected with $7.48 \%$. Among 74 skull fractures 61 were fissured and 13 were communited.

Among the meningeal injuries sub-dural hemorrhages were found in $65.3 \%$ followed by subarachnoid hemorrhages in 53\% of cases and extra-dural hemorrhages in $10.8 \%$

Middle cranial fossa is most commonly fractured and posterior cranial fossa is least affected.

Thoraco-Abdominal Injuries: Fractures are most frequent injury type of this region, 36 out of 147 cases, of which rib fractures constitute the most. Next common is injury to internal organs viz., 15/47. $9 \%$ of riders and $8 \%$ of pillions suffer pelvic fractures. $17.2 \%$ of riders and $20 \%$ of pillions acquired rib fractures.

Pattern of Fractures in Upper Limb: Among the fractures, radius and ulna suffered the most followed by humerus. The acromion and metacarpals were the least affected during road fatalities. Upper limb fractures are significantly higher in riders. P value $<0.05$.

Pattern of fractures in Lower Limb: Among the lower limb injuries, fractures are one of the most severe from viz., common in femur $(10.2 \%)$ followed by Tibia (8.1\%) which includes both bone fractures also. Foot fractures the least common.

Distribution of Fatal Injuries: Among the total fatalities 63.8\% suffer Meningeal haemorrhages, 13\% cerebral injuries, 51\% skull fractures, 6.8\% Spinal injuries, 10.8\% Lower limb fractures and 6.1\% Pelvic fractures. The commonest being the skull fractures (51\%). Followed by lower limbs, upper limbs, ribs, pelvic fractures.

Among the crush injuries $(7\{4.8 \%\})$ of the limbs, most involed are the lower limbs. The $4.9 \%$ of riders and $4 \%$ of pillions suffer crush injuries. 


\section{ORIGINAL ARTICLE}
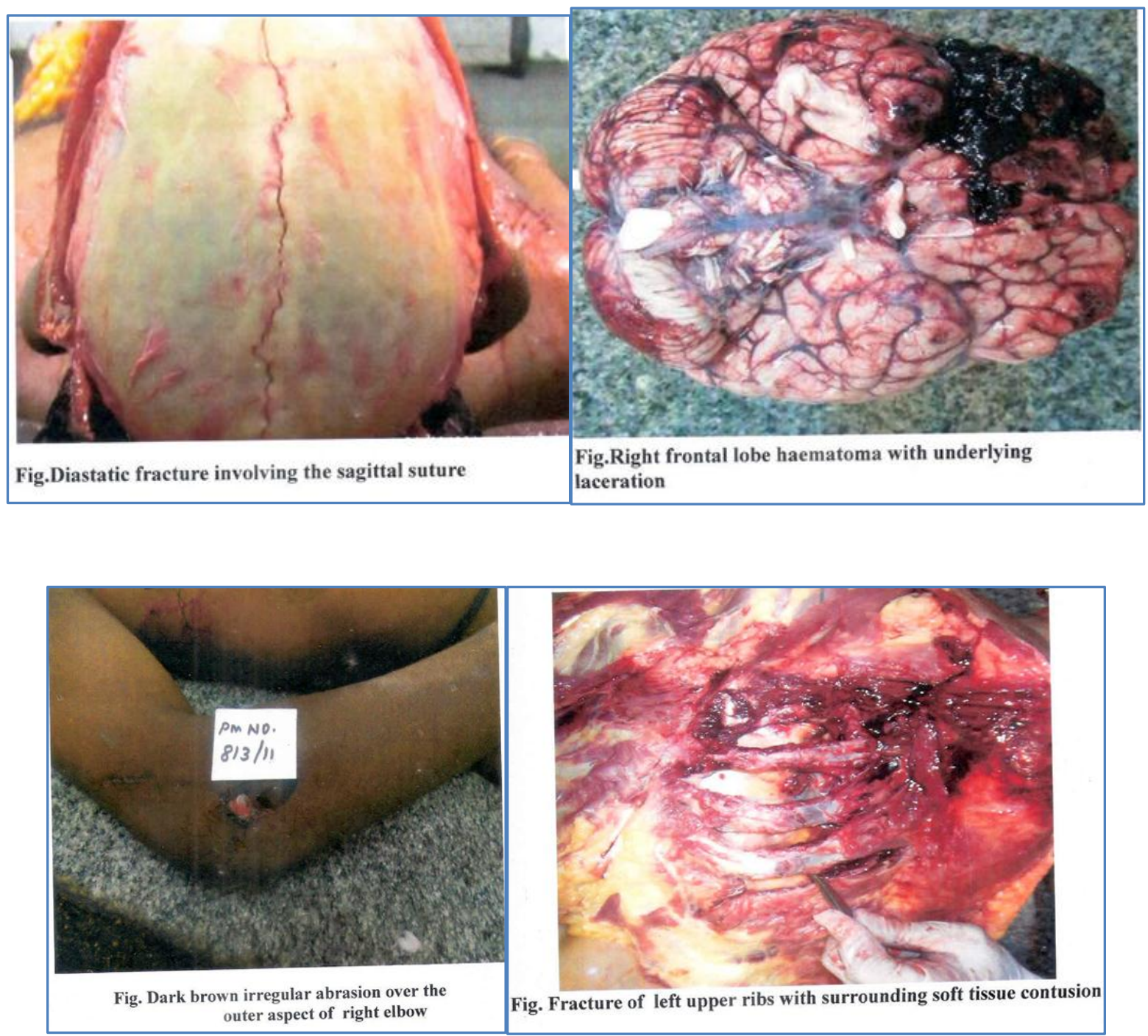

DISCUSSION: Age Distribution of the Study Sample: Among the age group 20 to 40yrs 101/147 680.7\%. Among them age 20 to 30yrs 65/101 64\% viz., supported well by many other studies.8,9,10,11, young drivers and riders coupled with inexperience are the main prey of road traffic accidents.

Sex Distribution of the Study Sample:In my study, 94\% were males which is well supported by other studies20,21. Since males are the bread winners of the family they have to look after the family.78\% of all fatalities occur during first three years of driving due to inexperience. ${ }^{12}$

Frequency of Riders and Pillion Riders:As riders are the most frequency travelers of two-wheelers than pillions, they are affected in almost every road traffic accidents. In our study $83 \%$ were riders and $17 \%$ were pillion riders.

Among the male population 138 of the study. Riders are 199(86\%). Pillion riders are $19(13.73 \%)$. Among female population, 3 out of $9(33.33 \%)$ were riders and $66.66 \%$ were pillion riders. This indicate that present study reveals similar to other study. 20 


\section{ORIGINAL ARTICLE}

Among the $94 \%$, of male, $86 \%$ were riders. $14 \%$ were pillion riders. Among $6 \%$ females, $67 \%$ were pillion riders $33 \%$. This reveals that $66 \%$ deaths of females were not due to their riding. Only $33 \%$ were due to their riding and other factors. But in males their own riding and factors contribute. So riders who determine the accidents which is consistent with other study. ${ }^{44}$ Motorcyclists are more prone for serious vulnerable road traffic accidents due to inherent instability of two wheeled vehicles. 36

Only 33\% were dead due to their riding and other factors. But in males, most of them were riding of their own. This reemphasize the fact that riders especially males are more prone to fatalities due to accidents.

Time of Accident: Our study reveals that the maximum proportion of accidents occur at the 2 peak hours of travel, i.e., between 6-11 AM and 6-10 PM. That too, more frequent in 6-10PM. Among the fatalities of the interval 6-11 AM the percentage of pillion riders are significantly higher when compared to other time intervals.

In the present study, the peak occurrence of the accidents is around 6-10PM viz supported by other study. ${ }^{12}$ Sleeplessness, fatigue and stress while returning from office contribute more to RTAs.

Around 29\% of two wheeler accidents occur between 6.00PM - 10.00 PM people return from office hours with mental stress, fatigue, driving at high speed consuming alcohol in the evening hours, invisibility of oncoming vehicles, pedestrians, animals, road medians, poor quality of roads, man holes, tree all factors contribute to occurrence of road traffic accidents. Around 11-3 PM, is the next peak incidence this reveals that the accidents are more prone to occur during day time, country to the common belief. The accidents are less likely to occur between 3-6 AM because of less traffic movement.

In about 27 victims (18.36\%) accident occurred 6-11 AM. In about 28(18.37\%) victims accidents occur 11 AM - 3PM. 21 cases accidents occur 3-11PM (12.92\%), nearly 35(23.80\%) accidents occur. 10PM-3.00AM 21 cases (14.28\%).

Manner of Accident: Head-on or frontal type of collisions are most common type of impact which proves fatal, followed by self-fall. The had-on collision or two vehicles can be possible when they are travelling on opposite direction. ${ }^{28}$ This can be prevented by strict traffic regulation and by diving the roads with median divider to make them single way roads.

The term "Self fall" is self-explanatory, as it implies that the victim who is travelling in the vehicle is solely responsible for the accident and none other viz., supported by many other study. ${ }^{11}$ Deaths due to self-fall are most frequent in time interval of 6-10 PM viz, due to various factors like dim nights, fatigue, stressed up mind set carried from the work, evening hurry to home etc.

Survival Period of the Victims:It is estimated that among road fatalities nearly $50-60 \%$ occur at the site of crash or while transfer to the hospital (First wave), 20-30\% during hospital stay (Second wave), 5-10\% after discharge from the hospital (Third wave). Neurological injury, hemorrhage and shock are the major cause of death.

Regional Distribution of Injuries:Majority of fatal two wheeler accident victims have received multiple external injuries. Multiple body parts were involved in each case. Abrasion, contusion, 


\section{ORIGINAL ARTICLE}

lacerations and fractures were seen over head neck, thoraco-abdominal and extremities. ${ }^{32}$ Multiple Injuries were commonly observed in fatal two wheeler accidents.

More frequently of secondary injuries seen in the motor-cyclists may be attributed to greater distance of fall in them. Even a single crash may lead to multiple primary impacts in a victim.

Head and extremities were the most common areas to suffer superficial injuries. Crush injuries predominantly seen in lower limbs.

Distribution of Abrasions: In our study abrasions are the most common type of injury in road traffic accidents even in all fatal cases which is also supported by other study. ${ }^{8}$ It is found that abrasion injuries were more common on the extremities. In the present study, abrasions are seen more in the extremities i.e., over the upper limbs and the lower limbs, followed by the head and neck region and thoraco-abdominal regions. This correlated with the parachute reflex i.e., when a conscious individual falls there will be reflex extension of all the four limbs to protect he head and torso which contains the vital organs.

Abrasions are seen in higher frequency on the right side in all the above regions in my study. This explains that, the tendency to balance the two wheeler is more effective on the left side than the right. So incidence fall and so as the injuries are more common on the right side of the victims.

Injuries of Head and Neck: Secondary injuries are more common in motorcyclists. More frequency of secondary injuries seen in the motor-cyclists may be attributed to a greater distance of fall in them. Even a single crash may lead to multiple primary impact in a victim. Primary impact injuries are most commonly seen in the lower extremities and pelvis, followed by upper extremities and shoulder, whereas abdomen, head and neck are less commonly involved regions. Secondary impact injuries are mostly seen in the head and neck and are followed by upper and lower extremities. Back and abdomen are the least involved and was observed as the same in a study involved 1642 secondary injuries. Maximum injuries are recorded in lower extremities, followed by head and neck and upper extremities. It is observed that number of secondary injuries is fairly high in fatal road traffic accidents. Crushing injuries are responsible for more incidences of secondary injuries. Contusion injuries were more common on the scalp tissue.

In the present study, meningealhemorrhages were seen in 105 cases. Riders constitute 89 whereas pillion riders 16. Subdural hemorrhages (Most common) seen in 96 cases $65 \%$ of the total victims, Sub Arachnoids hemorrhages in 78 cases, 53\%, Extramural hemorrhages in 16 cases, 10.8\% which is supported by other studies. ${ }^{11}$

The temporal bone was found to be most common vault bone to get fractured, as it is the thinnest vault bone.

Among the skull fractures committed fractures accounts to a significant fraction which implies the proportion of severe form of collision.

Thoraco-Abdominal Injuries: In general thorax and abdomen are safe. They are well protected by the extremities, which block any kind of harm to the trunk, if expected. Even trivial form of injury like abrasion is rare because of clothing's worn by the victim. But contusions and fractures were considerable among which rib fractures and chest wall bruising were forces, but not those due to perpendicular ones. The damage to the visceral organs are the most fatal. 
As secondary injuries are commoner than primary injuries in thorax and abdomen there is no significant difference among riders and pillions.

Injuries if Upper Limb:Pattern of Abrasions in Upper limbs: The abrasions seen over the body surface are often caused due to frication over the road surface on falling over the ground.Spits Graze abrasions occur when the victim's body is dragged against any rough surface like roads, wall etc.redd or due to the fall of the motor cycle over them. Elbow and forearm are often injured in motor cycle accidents. In the present study, the abrasions in this region might have been caused by either by handle bar or fall on the ground.

Pattern if Fractures in Upper Limbs: Injuries of Lower limbs: Legs are often injured in motor cycle accidents when the motorcycle dash with other vehicle or any fixed structures or the legs may be trapped in the motor cycle frame.

Pattern of Abrasions in Lower Limbs: In the present study, 116 victims out of 147, had abrasions in the lower limbs. Abrasions are commonly seen in the knee region irrespective of the type of ride. The highest incidence of abrasions in lower limbs both in riders and pillion riders are on the knees.

Pattern of Fractures in Lower Limbs: In the present study, fractures were seen in 29 victims, out of which femur fracture is 15 cases (10.20\%), tibia in 12 cases (8.16\%). But according to most other studies, commonest fracture in lower limb occurs in tibia. ${ }^{12}$ As we dealt with fatal cases alone and femur fracture is more fatal than that of tibia, most of the road traffic accident victims who sustained tibial fracture would have survived except few unfortunate ones, we came across.

Distribution of Fatal injuries: In the present study, Cranio-cerebral, the commonest cause of death which is similar to other studies.8,34 It's also noted that no significant difference in pattern of fatal head injuries among riders and pillion riders. That too Meningeal hemorrhages and cranial fractures are the most frequent fatal injuries than actual injury to the underlying brain substance.

On comparing the pattern of fatal injuries among riders and pillion riders the thoracoabdominal injuries like visceral damage and pelvic fractures were frequent. Whereas lower limb injuries are common in riders than in pillions viz., well supported by most of the studies. ${ }^{8,34}$

Frequency of Helmet Usage: In our study, most of the victims are non-helmet users (78.9\%). when compared to them, those who had worn helmet are protected from head injuries. This is reiterated by the findings that the head injury remains to be the most common cause of death among non-helmet users. $57.5 \%$ of non-helmet users died of head injuries, whereas only $11.56 \%$ of helmet users died of head injuries. Helmet users were comparatively protected from cranial injuries but not from spinal injuries. However, the major cause of death among helmet users was shock and hemorrhage due to skeletal injuries and visceral injuries.

Among the females percentage of helmet usage is far less when compare to male because, most of the female victims are pillions and they usually avoid or denied helmets.

Cause of Death:Among the RTA victims, cranio-cerebral injuries remains to be the most common killer (96\%). Unfortunately, 57.5\% victims were non helmet users. The second cause of death was 


\section{ORIGINAL ARTICLE}

due to multiple injuries. Lower limbs injuries and abdominal visceral injuries were the lowest fatal injuries among our sample.

Among the total death toll due to head injuries percentage of helmet users were significantly low (20\%), when compared to nom helmet users who were about $80 \%$ as in many other studies ${ }^{11}$. But, in death due to other causes helmet provides no protection at all. More over from the history collected in our study depicts that, most of the helmet users died in high energy collisions involving heavy and light weight motor vehicles. In contrast non helmet users succumbed to even relatively less energy accidents like self-fall.

\section{CONCLUSION:}

Among 1160 road traffic fatalities received from Jan-2011 to Nov-2011 in our instruction about 350 cases were victims of two wheeler accidents. Out of which 147 fatalities were studied and the following conclusion are drawn:

1) Majority of the vitims were males and especially riders.

2) Most of the victims belong to the age group 20-30 years.

3) Most of the accidents occurred around 6 PM - 10 PM.

4) Majority of accidents were frontal collisions.

5) Self fall accounts for a significant proportion of the total burden of two wheeler accidents, that too mostly around 6-10PM.

6) When compared with the time interval and number of fatalities, too many deaths occurred within 12 hrs of the accident.

7) All toys of injuries were highly frequent in head and neck region followed by extremities.

8) Most of the injuries occurred on the right side of the victim's bodies.

9) Among head injuries Meningeal haemorrhages ranks first, followed by scalp contusions and skull fractures.

10) Subdural haemorrhages were commonest among meningeal haemorrhages and temporal bone suffers most fractures sharing with middle cranial fossa.

11) Among the abrasions on upper limb elbow and forearm suffers the most. Fractures are also most frequent in the bones of forearm followed by humerus.

12) In case of lower limbs, knee was abraded the most. Femur was broken most frequently followed by tibia.

13) Though meningeal haemorrhages are the major fraction of all fatal injuries, among the fractures, the commonest was the skull fractures (49.6\%). Followed by lower limbs, upper limbs, ribs, pelvic fractures.

14) Vast majority of the road users were not wearing helmets and so the major cause of death in case of their fatalities are "Head Injuries". Skull fractures were most frequency in non helmet users.

15) Cause of death other than head injuries are more frequent in helmet users. Manner of accident is also more severe in fatalities of helmet users.

16) Majority of the vitims were males and especially riders.

17) Most of the victims belong to the age group 20-30 years.

18) Most of the accidents occurred around 6 PM - 10 PM.

19) Majority of accidents were frontal collisions. 


\section{ORIGINAL ARTICLE}

20) Self fall accounts for a significant proportion of the total burden of two wheeler accidents, that too mostly around 6-10PM.

21) When compared with the time interval and number of fatalities, too many deaths occurred within $12 \mathrm{hrs}$ of the accident.

22) All toys of injuries were highly frequent in head and neck region followed by extremities.

23) Most of the injuries occurred on the right side of the victim's bodies.

24) Among head injuries Meningeal haemorrhages ranks first, followed by scalp contusions and skull fractures.

25) Subdural haemorrhages were commonest among meningeal haemorrhages and temporal bone suffers most fractures sharing with middle cranial fossa.

26) Among the abrasions on upper limb elbow and forearm suffers the most. Fractures are also most frequent in the bones of forearm followed by humerus.

27) In case of lower limbs, knee was abraded the most. Femur was broken most frequently followed by tibia.

28) Though meningeal haemorrhages are the major fraction of all fatal injuries, among the fractures, the commonest was the skull fractures (49.6\%). Followed by lower limbs, upper limbs, ribs, pelvic fractures.

29) Vast majority of the road users were not wearing helmets and so the major cause of death in case of their fatalities are "Head Injuries". Skull fractures were most frequency in non-helmet users.

30) Cause of death other than head injuries are more frequent in helmet users. Manner of accident is also more sever in fatalities of helmet users.

Other than these huge death toll to road traffic accidents, it is also estimated that, the economic loss due to the total traffic accidents in India accounts for about $2 \%$ of its gross domestic product. In the last decade the total road traffic fatalities were almost equal in both India and European countries. But, the later understood the severity of the situation and revised their road safety policies and by implementing various safety measures, they reduce the fatalities by about $50 \%$. But India witnessed a raise of about $50 \%$ in road traffic fatalities, increasing the mortality risk by 5 folds on the roads than elsewhere.

As the economic growth along with the vehicular population, overrides the speed of advancement of the safety measures, it is almost not possible to reduce the road traffic fatalities. So, we are in a crucial moment to prove our immediate intervention to improve the quality of road infrastructure, technology of vehicular safety and their quality, ease of accessibility of immediate medical care by redefining our health policies and legislation.

RECOMMEDATIONS: Need for Road Safety Policies: Road safety policy is nothing but the statement of various steps to be undertaken to achieve the visualized targets, set in this field to tackle identified safety issues. Road traffic accidents are preventable. Significant number of road traffic fatalities and injuries are not a fundamental law of nature or inevitable result of motorization. Other countries have been successful in improving their road safety by adopting road safety action force essentially needed for the major reduction in road traffic fatalities in those countries.

The first three policies among the 11-elements for road safety policies under the vision Safer Roads For Everyone include. 
1. Raising awareness about road safety issues among decision makers, citizens and road users. 2. Provision of Legislature, Institutional and Financial base for road safety. 3. Development of road safety information database. Other elements include road infrastructure, vehicles, derivers, road safety education and training. These policy statements adopted as National Road Safety Policy which serve as guidelines for road safety planning and programming at National, State and Local levels. In India, The National Road Safety council (NRSC) is under the chairmanship of the Minister in-charge of Road transport and Highways at the centre is an overall high level advisory body.

We, citizens of India must prevent the Road Traffic Accidents to rank third place in the year 2020.

RTA must be consider like other notifiable diseases. Reports should be collected from the primary health centre level to Tertiary hospital level on a weekly basis. Road Safety Campaigns should be frequently conducted. Police Officials must seriously enforce the laws considering the road safety. Fine on those persons not wearing helmet, more than two persons travelling per bike, persons using cell phones while riding, those who ride at excessive speed, testing for alcohol etc. Transport Authorities must take measures to laid down new roads, improve the quality of old roads, sufficient road, ensure if signals working properly in all places etc. Illumination must be sufficient for riding during the night time, higher number of traffic police for guiding and enforcing the rules and regulations since more number of accidents occur during the night time. Measures to prevent pedestrians and animal interventions in the traffic. All State governments must ensure the accessibility and availability of Emergency Trauma Care, increasing the Ambulance service, sufficient number of doctors at all specialties, appropriate emergency medical care etc. Education regarding the traffic rule should be a separate curriculum. We must all join together to bring down, eliminate and eradicate the road traffic accidents by 2020.

\section{BIBLIOGRAPHY:}

1. "All the info you need on lane sharing (lane splitting)" www.WhyBike.com. http://www.whybike.com/motorcycle274.Retrieved 28 June 2007. 20 Anna Maria Kalli, Elias AissarSallum, Cristiance de AlencarDomingue.

2. Douglas Bowley, Kenneth Boffard Pattern of injury in motor vegicek accidents Pattern of injury in motor vehicle accidents.

3. World Report on Road Traffic Injury Prevention - WHO Geneva 2004.

4. NHTSA: Motorcycles Traffic Safety Fact Sheet (DOT-HS-1200 New Jersey Avenue SE., Washington, DC 20590: 810-990).

5. "Motorcylistis -Crashes". Australian Transport "Motorcyclisits - Crashes". Australian Transport Safety Bureaus (ATS). 2005

http://www.transport.sa.gov.au/rss/content/safer+people/road_users/motortcyclists_crash es.htmrt Safety Bureau (ATS).

6. Harry Hurt, University of Southern California, Grease and Gasoline, 30 Nov 2011 cause of preventable injury.

7. Motorcycle Accident Cause Factors and Identification of Countermeasures, Volume 1: Technical Report, Hurt, H.H., Ouellet, J.V. and Thom, D.R., Traffic Safety Center, University of Southern Califiornia, Los Angeles, California 90007, Contract No. DOT HS-5-01160.

8. Nilambarjha, DK srinivasa, Gautam Roy, S Jagdish Year: 2003 Volume: 28 Page: 85 Injury Pattern among Road Traffic Accident Cases. 
9. ZengHao Wong, 1MBBS, CheeKeong Chong, 2 MBBS, FRCS (Edin) FRCS (Glas), Bee Choo Tai, 3 Msc, PhD Gilbert Lau, 4FAMS, MRC Path DMJ (path). Review of fatal road traffic accident from Singapore from 2000 to $2004=$. Annals Academy of Medicine. 2009.38: 594-9

10. Jain A, Menezes RG, Kanchan T, Gagan S, Jain R. Two wheeler accidents on Indian roads--a study from Mangalore, India. J Foresnsic Leg Med. 2009 Apr; 16(3): 130-3. Epub 2008 Oct 22.

11. Michael Fitzharris ${ }^{1,2,3}$, RakshiDandona*1,4,5, G.Anil Kumar ${ }^{4,5}$ and Lalit Dandona ${ }^{1,4,5}$ Crash characteristics and patters of injury among hospitalized motorized two-wheeled vehicle users India. BMC Public Health 2009, 9: 11 doi: 10.1186/1471-2458-9

12. Kortor JN, Yinusa W, Ugbeye ME. Lower limb injuries arising from motorcycle crashes. Niger J Med. 2010 Oct-Dec; 19(4): 475-8. rt Safety Bureau(ATS)

13. Menon A, Pai VK and Pajeev A. Pattern of fatal head injuries due to vehicular accidents in Mamgalore. J Forensic Leg Med. 2008; 15(2): 75-7.

14. Zargar M, Khaji A. Karbakhsh M. Pattern of motor cycle related injuries in Tehran. 1999 to 2000: a study in 6 hospitals. East Mediterranian Health J. 2006 Jan-Mar: 12 (1-2): 81-7

15. Dischinger PC, Ryb GE, Ho SM, Braver ER. Injury patters and severity among hospitalized motorcyclists: a comparison of younger and older riders. AnnuProcAssocAdvAutomot Med 2006; 50: 226-38

16. David Dolinak, Evan Matshes, Emma Lew, - Text book of forensic pathology-principles and practice 2005-ch 11 page no 259 Motor vechile collisions.

17. Martin JL, lafont S, Chiron M, Gadegbeku B, Differences between males and females in traffic accident risk in France, Rev EoidemionlSanterPublique. 2004 Sep; 52(4): 357-67

18. Oginni FO, Ajike SO, Obuckewe ON, Fasola O. A prospective multicenter study of injury profile, severity and risk factors in 221 motorcycle-injured Nigerian maxillofacial patients. Traffic Injury Prev. 2009; 10(1); 70-756. Trauma 14: 187-196; 1974

19. Valent F, Di Bartolomeo S, Marchetti R, Sbrojavacca R, Barbone F. A case-crossover study of sleep and work hours and the risk of road traffic accidents. Sleep. 2010 Mar; 33(3): 349-54

20. Cherpitel CJ. Alcohol and injuries: a review of international Emergency room studies. Addiction 1993; 88: 923-37

21. Cherpitel CJ, Bond J. Ye Yu, et al. A cross-national meta-analysis if alcohol and injury: data from the emergency room collaborative alcohol analysis project (ERCAAP) (2003). Society for the study of addiction to alcohol and other drugs. Addition 2003; 98: 1277-86.

22. G.Gururaj ROAD TRAFFIC INJURIES ALCOHOL AND ROAD TRAFFIC INJURIES IN SOUTHASIA: CHALLENGES FOR PREVENTON JCPSP 2004 Vol. 14(12): 1-2

23. R.R.Tiwari, G.B. Ganveer. A study on human risk factors in non-fatal road traffic accidents at Nagpur. Indian Journal of Public Health Vol. 52 No 4 October-December, 2008 197-8.

24. hui Zhao, Rong Chen, Guijing Deng, Zhiyoung Yin, Guangyu Yang, Shengziong Liu, Huipeng Chen, Zhengguo Wang. Comparison of injuries sustained by drivers and pillion passengers in fatal head-on motorcycle collision accidents. Forensic science international (impact factor: 2.1). 10/2010; DOI: 10.1016 j.forsciint.2010.10.0033

25. Anish Sam George, MuraliPoduval, Analysis of Limb Injury Patterns in Victims of Two Wheeler Accidents. Asian Journal of Medical Sciences Vol.1 (1) 2010 p.14-15

26. R Dandona,G A Kumar T.S Raj, and L Dandona patterns of road traffic injuries in a vulnerable population in Hyderabad, India Injury prevention 2006 June; 12(3): 183-188 


\section{ORIGINAL ARTICLE}

27. Zargar M, Khaji A. Karbakhsh M. Pattern of motor cycle related injuries in Tehran. 1999 to 2000: a study in 6 hospital. East Mediterr Health J. 2006 Jan-Mar: 12(1-2): 81-7

28. Peek-Asa C, Krasus JF, Injuries sustained by motorcycle riders in the approaching turn crash configuration, Acc. Annal and Prev., 28(5), 561-9,1996

29. Dandona R, Kumar GA, Dandona L. Risky behaviour of drivers of motorized two wheeled vehicles in India. J Safety Res 2006; 37(2): 149-58. Epub 2006 May.

30. Javouhey E, Guerin AC \& Chiron m, Incidence and risk factors of severe traumatic brain injury resulting from road accidents: A population-based study. Accident Analysis Prevention. 2006. 38: $225-233$.

31. de Oliveira NL, de Sousa RM (Rev Lat Am Enfermagem. 2011 Aor; 19(2): 419(2): 403

32. Susan Wells er al. (April 10, 2004). "Motorcycle rider conspicuity and crash related injury: case-control study". BMJ.

http://www.bmj.com/cgi/content/full/328/7444/857. Retrieved 2007-06-26. Abstract, Quick summary.

33. Redelmeier DA, Tibshirani RJ, and Dr.S.S>0beroi, Dr.K.K.Aggarwal, Dr.D.S.Bhullar, Dr.R.Kumar, PATTERN AND DISTRIBUTION OF INJURIES IN FATAL TWO WHEELER AC CIDENTAL CASES. Journal of Punjab Academy of Forensic Medicine \& Toxicology 10(2010)

34. Dr.S.S.Oberoi, Dr.K.K.Aggarwal, Dr.D.S.Bhullar, Dr.R.Kumar, PATTERN AND DISTRIBUTION OF INJURIES IN FATAL TWO WHEELER ACCIDENTAL CASES. Journal of Punjab Academy of Forensic Medicine \& Toxicology 10(2010). C Haasper; D otte; KKnobloch; J Zeichen; C Krettek; M Richter. Knee injuries of vulnerable road users on road traffic. Der Unfallchirurg 2006; 109(12): 1025-31.

35. H Markogiannakis, E Sanidas, E Messaris, D Koutentakis, K Alpantaki, AKafetzakis, D Tsiftsis. Motor vehicle trauma: analysis of injury profiles by road-user category. Emerg Med J 2006; 23: 27-31 Doi: 10.1136/emj.2004. 022392.

36. Fatal road traffic accidents and their relationship with head injuries, 2008. 63. Fatal road traffic accidents and their relationship with head injuries: An epidemiological survey of five years. Arvind Kumar MD, SanjeevLakwani MD,

http: //www.ijntonline.com/Dec08/abstracts/abs2.PDF

37. DR KS Narayana Reddy, Dr KSNarayana Reddy, the essential of Forensic Medicine and Toxicology, 30th Edition 2011 Ch-6 P.163.

38. AkhileshPathak, N.L. Desania and Rajesh Verma. Profile of road traffic accidents and Head Injury in Jaipur (Rajasthan).J. Indian Acad Forensic Med, 30(1).

39. Asla, M, Taj TM, Ali SA, Miza WA, Badar N. Non-fatal limb injuries in motorbike accident. L Coll Physicians Surg Pak. 2008 Oct; 18(10): 635-8

40. Calil AM, Sallum EA, Dominigues CA, Nogueira LS. Mapping injuries in traffic accidents victims: a literature review. Rev latino-am Enfermagem 2009 janeiro-fevereiro; 17(1): 120125.

41. Lateef F, Riding motorcycles: is it a lower limb hazard? Singapore Med J. 2002 Nov; 43(11): 566-9

42. Singh YN, Bairagi KK \& Das KC. An epidemiological study of road traffic accidetn victims in medicolegal autopsies. J Indian Acad Forensic Med. 2005; 27(3): 166-69.

43. E,Th.Petridou, E.Germeni, A.Ntinapogias, The European Code Against Injuries (ECAI), Archives of Helenic Medicine, vol 25, supplement 1, 2008. 


\section{ORIGINAL ARTICLE}

44. Australian Institute of Family Studies, TAC \& RAVCV, ATP Young Drivers Study 2002.

\section{AUTHORS:}

1. M. Seethalakshmi

2. R. Sudalaimuthu

3. J. Mahendran

4. A. Nagendrakumar

\section{PARTICULARS OF CONTRIBUTORS:}

1. Assistant Professor, Department of Forensic Medicine, Tirunelveli Medical College, Tirunelveli.

2. Associate Professor, Department of Forensic Medicine, Tirunelveli Medical College, Tirunelveli.

3. Associate Professor, Department of Forensic Medicine, Savitha Medical College and Hospital, Kanchipuram.

FINANCIAL OR OTHER COMPETING INTERESTS: None
4. Assistant Professor, Department of Forensic Medicine, Govt. Vellore Medical College, Vellore.

\section{NAME ADDRESS EMAIL ID OF THE CORRESPONDING AUTHOR:}

Dr. R. Sudalaimuthu, G1, Grace Apartments, 19, North High Ground Road, Palayamkottai-627002,

Tirunelveli, Tamilnadu.

E-mail: rsmuthu6@rediffmail.com

Date of Submission: 26/08/2015.

Date of Peer Review: 27/08/2015.

Date of Acceptance: 18/09/2015.

Date of Publishing: 24/09/2015. 